\title{
Evidence That HFE H63D Variant Is a Potential Disease Modifier in Cluster Headache
}

\author{
Maria Papasavva $^{1} \cdot$ Michail Vikelis $^{2} \cdot$ Martha-Spyridoula Katsarou $^{1} \cdot$ Vasileios Siokas $^{3} \cdot$ Emmanouil Dermitzakis $^{4}$. \\ Christoforos Papademetriou ${ }^{1} \cdot$ Konstantinos Karakostis $^{5}$. George Lazopoulos ${ }^{6}$. Efthimios Dardiotis $^{3}$. \\ Nikolaos Drakoulis ${ }^{1}[0$
}

Received: 7 July 2021 / Accepted: 2 September 2021 / Published online: 27 September 2021

(c) The Author(s) 2021

\begin{abstract}
Cluster headache $(\mathrm{CH})$ is a primary headache disorder with a complex genetic background. Several studies indicate a potential link between iron homeostasis and the pathophysiology of primary headaches. The $H F E$ gene encodes for a protein involved in iron metabolism, while genetic variants in $H F E$ have been associated with hereditary hemochromatosis (HH), an iron overload disorder. The objective of the current study was to examine the association of the more common HFE H63D variant, with the susceptibility to develop $\mathrm{CH}$ and diverse clinical phenotypes in a population of Southeastern European Caucasian (SEC) origin. Genomic DNA samples from $128 \mathrm{CH}$ patients and 294 neurologically healthy controls were genotyped for the HFE rs1799945 (H63D) variant. H63D genotypic and allelic frequency distribution did not differ significantly between patients and controls $(p>0.05)$. Subgroup analysis revealed a significantly more frequent occurrence of the variant $\mathrm{G}$ allele in chronic compared to episodic $\mathrm{CH}$ patients, indicative for a possible correlation of the $H F E$ gene with the susceptibility for disease chronification. Although homozygosity for the less prevalent $\mathrm{H} 63 \mathrm{D}$ variant $\mathrm{G}$ allele was minimal in the $\mathrm{CH}$ cohort, the results of the present study are in accordance with previous studies in $\mathrm{CH}$ and migraine patients, suggesting that HFE H63D variant modifies the disease clinical characteristics. Hence, despite the absence of a per se association with $\mathrm{CH}$ susceptibility in the current SEC cohort, variability in $H F E$ gene may be potentially regarded as a disease modifier genetic factor in $\mathrm{CH}$.
\end{abstract}

Keywords Primary headache disorders · Genetics · Iron homeostasis · rs $1799945 \cdot$ H63D $\cdot$ Southeastern European Caucasians

Nikolaos Drakoulis

drakoulis@pharm.uoa.gr

1 Research Group of Clinical Pharmacology and Pharmacogenomics, Faculty of Pharmacy, School of Health Sciences, National and Kapodistrian University of Athens, Panepistimiopolis Zografou, 15771 Athens, Greece

2 Headache Clinic, Mediterraneo Hospital, Glyfada, Greece

3 Department of Neurology, Laboratory of Neurogenetics, University Hospital of Larissa, Greece, Faculty of Medicine, School of Health Sciences, University of Thessaly, Larissa, Greece

4 Neurologist, Thessaloniki, Greece

5 iDNA Genomics Laboratory, Athens, Greece

6 Department of Cardiothoracic Surgery, University General Hospital of Heraklion, Medical School, University of Crete, 71003 Heraklion, Greece

\section{Introduction}

Cluster headache $(\mathrm{CH})$ is a debilitating primary headache disorder, classified in the group of trigeminal autonomic cephalalgias (TACs) and affecting around $0.1-0.4 \%$ of the general population (Snoer et al. 2018). The pain attacks in $\mathrm{CH}$ are described as excruciating, strictly unilateral, lasting between 15 and 180 min and usually occurring in bouts up to 8 times daily with a circadian and circannual periodicity (Láinez and Guillamón 2017; Liampas et al. 2020). Ipsilateral, prominent, and consistent cranial autonomic symptoms are accompanying $\mathrm{CH}$ attacks (Vikelis and Rapoport 2016; Goadsby 2018). According to the criteria developed by International Classification of Headache Disorders 3rd edition (ICHD-3), $\mathrm{CH}$ can be sub-diagnosed as episodic (eCH) or chronic $(\mathrm{cCH})$. In a small proportion of patients (about $10 \%), \mathrm{CH}$ attacks are characterized as chronic, occurring in bouts lasting one year or more without remission or with 
pain-free periods lasting less than 3 months (Headache Classification Committee of the International Headache Society (IHS) 2018).

Although $\mathrm{CH}$ is considered a neurovascular disorder with hypothalamic activation and trigeminal-autonomic reflex playing a predominant role in disease manifestation, its complex pathophysiology is still partially understood. Population, family, and twin studies support a heritable component for this primary headache, with increased risk for developing $\mathrm{CH}$ in first- and second- degree relatives compared to the general population and higher concordance in monozygotic twins (Russell 2004; Gibson et al. 2019); thus, potential genetic risk factors seem to predispose to $\mathrm{CH}$ development (O'connor et al. 2020; Waung et al. 2020). Consequently, many studies endeavored to discover the genetic components implicated in the etiopathology of $\mathrm{CH}$. Most genetic association studies investigated variants in candidate genes inferred to be involved in the observed $\mathrm{CH}$ pathophysiology-related molecular pathways and/or associated with other primary headache disorders, particularly migraine (Sjöstrand et al. 2002; Pinessi et al. 2005; Schürks 2010; Zarrilli et al. 2015; Ran et al. 2017, 2020; Fan et al. 2018; Fourier et al. 2019; Gibson et al. 2019; Papasavva et al. 2020).

The most frequent type of hereditary hemochromatosis $(\mathrm{HH})$, an endocrine disorder of iron overload, is associated with mutations in the HFE gene. The HFE (high Fe) gene, located in chromosome 6 (6p21.3), encodes for an atypical major histocompatibility complex (MHC) class Itype glycoprotein (Nixon et al. 2018; Pantopoulos 2018). HFE protein is implicated in iron homeostasis by interacting with transferrin receptor 1 (TfR1) on cellular membranes and thereby negatively regulates transferrin-mediated iron uptake. HFE interacts also with TfR 2 and probably additional protein molecules, such as hemojuvelin (HJV) and bone morphogenetic proteins (BMPs) and their receptor (BMPR) via the BMP/small mothers against decapentaplegic (SMAD) signaling pathway, shaping a putative iron-sensing complex that upregulates hepcidin expression, the major negative regulatory hormone of systemic iron homeostasis (Kent et al. 2015; Wu et al. 2015; Jiang et al. 2017; Traeger et al. 2018; Katsarou et al. 2019). Excessive iron stores, elevated plasma iron levels, and inflammation induce hepcidin synthesis whereas is suppressed by hypoxia and erythropoietic drive such as iron deficiency anemia (IDA) (Stoffel et al. 2019). Two missense variants in the coding-region of the $H F E$ gene are responsible for the majority of $\mathrm{HH}$ cases: the rs 1800562 (C282Y) in exon 4 , a G to A transition at nucleotide position 845 resulting in a cysteine to tyrosine substitution at amino acid 282, which abrogates HFE protein from reaching the cell surface and interacting with TFRs and hepcidin, and the rs1799945 (H63D) in exon 2, a C to $\mathrm{G}$ transition at nucleotide 187 resulting in histidine to aspartic acid substitution at amino acid 63 , which reduces the affinity of the altered protein for TfR1 (Barton et al. 2015; Katsarou et al. 2016; Wang et al. 2017). Hence, due to malfunctioning in BMP/SMAD pathway of patients with HFE $\mathrm{HH}$ and $\mathrm{Hfe}-/-$ mice, the expression of hepcidin is inappropriately decreased and the response of hepcidin to iron intake is diminished (Pantopoulos 2008, 2018).

Various studies investigated the potential role of iron homeostasis in brain disorders and specifically primary headaches, with some reports indicating a link between elevated iron levels in brainstem pain-processing structures and primary headaches. Welch et al. reported enhanced iron levels in the periaqueductal gray matter (PAG), a descending antinociceptive-modulating center, of episodic migraine patients with and without aura and in patients with chronic daily headache, that further elevate with the duration of the disease (Welch et al. 2001). In line with these findings, Kruit et al. showed enhanced iron deposition in multiple central pain mediating-nuclei, predominantly in putamen, globus pallidus, and red nucleus, with higher iron accumulation in migraineurs with longest disease history (Kruit et al. 2009). Conversely, the 9-year follow-up study failed to provide supportive evidence for progressive iron accumulation in deep brain nuclei related to migraine; nevertheless, the authors explained that these findings may be attributed to age-related iron increase, thus age can serve as conflicting factor (PalmMeinders et al. 2017). Tepper et al. confirmed the association between increased iron deposition in basal ganglia, particularly in globus pallidus, and migraine risk as well as attack frequency and disease duration (Tepper et al. 2012). A more recent study supported the hypothesis of an increased iron deposition in basal ganglia nuclei, especially red nucleus and PAG, in chronic migraine patients (Domínguez et al. 2019). Few studies indicated an association between IDA and migraine incidence, particularly in females (GürÖzmen and Karahan-Özcan 2015; Tayyebi et al. 2019). Furthermore, a large study in a Norwegian population indicated that phenotypic hemochromatosis, a progressive iron overload disease, and/or HFE C282Y/C282Y genotype carriers were both associated with increased headache prevalence among female participants (Hagen et al. 2002). Coexistence of migraine and $\mathrm{CH}$ has been documented in some patients and a genetic link for these primary headache disorders has been suggested (Kudrow and Kudrow 1994; D'Amico et al. 1997). Lastly, hereditary haemochromatosis was reported in two cousins with $\mathrm{CH}$, while normalization of iron deposits improved temporarily $\mathrm{CH}$ attacks (Stovner et al. 2002). Consequently, if elevated iron levels in the brain painmodulating areas are implicated in headache pathophysiology, the co-existence of hemochromatosis could potentially have an impact on disease progression or development. Although the more common HFE H63D variant rarely causes $\mathrm{HH}$, it is suggested to be a disease risk and progression modifier for several neurological disorders (Kim and 
Connor 2020). Thus, the HFE H63D variant serves as an interesting candidate genetic variant for $\mathrm{CH}$ susceptibility.

The aim of the current association study was to examine whether the rs 1799945 (H63D) HFE variant might confer susceptibility to develop $\mathrm{CH}$ and/or diverse disease phenotypes in a cohort of Southeastern European Caucasian (SEC) $\mathrm{CH}$ patients and neurologically healthy control subjects.

\section{Subjects and Methods}

Study Population A total of 128 unrelated SEC CH patients (95 males and 33 females), aged between 22 to 68 years (mean \pm standard deviation: $41.7 \pm 10.3$ years; $75.8 \%$ male) served as $\mathrm{CH}$ group. The diagnosis of $\mathrm{CH}$ was carried out by experienced neurologists according to the International Classification of Headache Disorders criteria (ICHD-3). The main clinical characteristics of $\mathrm{CH}$ cohort and demographic data for the study population are summarized in Table 1. Case subjects were recruited from specialized headache clinics located in Glyfada and Thessaloniki, Greece. Two hundred ninety-four unrelated neurologically healthy SEC control subjects (149 males, 145 females) with no personal and family history of migraine or any other headache disorder, aged between 21 to 85 years (mean \pm standard deviation: $57.3 \pm 13.0$ years; $50.7 \%$ male) were recruited from the Neurology Department, University Hospital of Larissa, Greece. Data collected from control subjects included only age and gender. All study subjects were South-eastern European Caucasians. A written informed consent was provided by each study subject. The research was performed in accordance with the principles outlined in the Declaration of Helsinki. The study protocol was reviewed and approved by the appropriate Ethics Committees (Mediterraneo Hospital, Glyfada, Greece, and University Hospital of Larissa).

DNA Purification and Genotyping Epithelial cells from the oral cavity of the study subjects were collected by sterile buccal swabs. Genomic DNA was extracted from the epithelial cells with the Nucleospin Tissue DNA Mini Kit (Macherey-Nagel GmbH \& Co., KG, Düren, Germany) according to the manufacturer's protocol. DNA concentration in the purified samples was quantified by NanoDrop One Spectrophotometer (Thermo Fischer Scientific), and the samples were stored in $-20{ }^{\circ} \mathrm{C}$ until screening of the selected $H F E$ variant. H63D (rs1799945) genotypes of each participant were determined by the SNP TaqMan qPCR method using the Applied Biosystems QuantStudio 12 K Flex RealTime PCR System.

Statistical Analysis Continuous variables are shown as mean \pm standard deviation (SD). Categorical variables are presented as frequencies $(n)$ and percentages (\%). Chisquare $\left(\chi^{2}\right)$ (Pearson or Fischer's exact when appropriate) tests were used to compare H63D variant frequency distribution between groups and $\mathrm{CH}$ subgroups under codominant, dominant, over-dominant, recessive genotypic, and allelic inheritance models. Multivariable logistic regression analysis was used to adjust for potential confounding factors including age and gender as covariates, to exclude any bias due to the skewed age distribution and gender ratio between the groups. The crude and adjusted odds ratios (OR) with the corresponding $95 \%$ confidence intervals (CI) were calculated to estimate the risk derived from statistically significant differences. Statistical analysis of the data was carried out using version 26.0 of the IBM SPSS Statistics software for Windows. All $p$-values were two-sided, and values less than 0.05 were considered statistically significant. The web-based PS: power and sample size calculation program (v3.1.6), was used for power analysis (https://vbiostatps.app.vumc.org/ps/). With the available sample size and a minor allele frequency (MAF) of 0.14 , true odds ratios (OR) below 0.32 or above 2.13 can be detected for $\mathrm{CH}$ cohort with $80 \%$ power (Dupont and Plummer 1990). Deviation from the Hardy-Weinberg Equilibrium (HWE) in control subjects was assessed with the web-based Online Encyclopedia for Genetic Epidemiology studies software (Rodriguez et al. 2009).
Table 1 Demographic and clinical characteristics of the study population

\begin{tabular}{|c|c|c|c|}
\hline & CH patients $(N=128)$ & & Controls $(N=294)$ \\
\hline Age $($ mean $\pm S D)$ & $41.7 \pm 10.3$ ranged from 22 to 68 years & & $\begin{array}{l}57.3 \pm 13.0 \text { ranged } \\
\text { from } 21 \text { to } \\
85 \text { years }\end{array}$ \\
\hline Gender $(\mathrm{M} / \mathrm{F})$ & $95 / 33$ & & $149 / 145$ \\
\hline $\mathrm{BMI}(\mathrm{mean} \pm \mathrm{SD})$ & $25.8 \pm 4.5 \mathrm{~kg} / \mathrm{m}^{2}$ & & - \\
\hline Age of diagnosis $($ mean \pm SD) & $37.1 \pm 10.8$ ranged from 18 to 65 years & & - \\
\hline Positive family history & 57 & $(44.5 \%)$ & - \\
\hline \multicolumn{4}{|l|}{ Type of CH } \\
\hline ECH & 88 & $(68.8 \%)$ & - \\
\hline $\mathrm{CCH}$ & 40 & $(31.2 \%)$ & - \\
\hline
\end{tabular}


Table 2 Genotypic and allelic frequency distribution of HFE H63D variant in cluster headache patients and control subjects

\begin{tabular}{|c|c|c|c|c|c|c|c|c|}
\hline & \multicolumn{4}{|c|}{ CH patients $(N=128)$} & \multicolumn{4}{|c|}{ Controls $(N=294)$} \\
\hline & Male & Female & Total & & Male & Female & Total & \\
\hline H63D rs1799945 & $(n=91)$ & $(n=32)$ & $(n=123)$ & $\%$ & $(n=149)$ & $(n=145)$ & $(n=294)$ & $\%$ \\
\hline $\mathrm{CC}$ & 69 & 21 & 90 & $(73.2)$ & 116 & 104 & 220 & $(74.8)$ \\
\hline GC & 19 & 10 & 29 & $(23.6)$ & 27 & 39 & 66 & $(22.4)$ \\
\hline GG & 3 & 1 & 4 & $(3.3)$ & 6 & 2 & 8 & $(2.7)$ \\
\hline Missing & 4 & 1 & 5 & & & & - & \\
\hline $\mathrm{C}$ & 157 & 52 & 209 & $(85.0)$ & 259 & 247 & 506 & $(86.1)$ \\
\hline G & 25 & 12 & 37 & $(15.0)$ & 39 & 43 & 82 & (13.9) \\
\hline
\end{tabular}

\section{Results}

\section{Genotype and Allele Frequency Distribution analysis} Between Cases and Controls The genotypic call rate for HFE H63D (rs1799945) was 98.8\%. Consistency with HWE in the control group was verified for the HFE variant $(p>0.05)$. The genotype and allele frequencies of the investigated genetic variant in $\mathrm{CH}$ patients and controls are presented in Table 2. Chi-square test and logistic regression analysis with age and gender as covariates showed no statistically significant difference in genotypic and allelic frequency distribution of the HFE H63D variant between case and control subjects, in any of the genetic inheritance model tested $(p>0.05)$, possibly indicating an absence of association between $\mathrm{H} 63 \mathrm{D}$ variant and susceptibility to $\mathrm{CH}$ in the current SEC population. (Table 3).

Subgroup Analysis According to $\mathrm{CH}$ Clinical Phenotypes In order to investigate the association between $H F E$ H63D variant and diverse $\mathrm{CH}$ phenotypes, patients were stratified into subgroups according to the form of $\mathrm{CH}$ (episodic/chronic) and the frequency of attacks. The $\mathrm{CH}$ group included 85 (69.1\%) patients diagnosed with episodic $\mathrm{CH}$ form and 38 (30.9\%) chronic $\mathrm{CH}$ patients. A statistically significant correlation between the HFE H63D and CH type was revealed.
As listed in Table 4, the frequencies of both CC genotype and $\mathrm{C}$ allele in $\mathrm{CH}$ cohort were significantly higher in patients with episodic compared to chronic $\mathrm{CH}$ patients (OR [95\% CI] 2.428 [1.055-5.584], $p=0.034$ dominant genotypic model and OR [95\% CI] 2.161 [1.059-4.410], $p=0.032$ allelic model). The difference remained significant after adjustment for age and gender (OR [95\% CI] 2.443 [1.051-5.679], $p=0.038$ dominant model). Consequently, $\mathrm{CH}$ patients homozygous (CC) for the H63D C allele may be at lower risk for disease chronification compared to carriers of the H63D G allele. No statistically significant association of the HFE H63D variant with the frequency of $\mathrm{CH}$ attack occurrence was detected in the current SEC CH cohort (data not shown).

\section{Discussion}

The current study examined the association of H63D (rs1799945) variant in the HFE gene with the susceptibility to develop $\mathrm{CH}$ and diverse clinical phenotypes, in a SEC case-control population. Genotypic and allelic frequency distributions of the H63D genetic variant were similar between patients and control subjects, indicating no
Table 3 Frequency distribution analysis in cluster headache patients and control subjects for the $H F E \mathrm{H} 63 \mathrm{D}$ variant

\begin{tabular}{lllll}
\hline $\begin{array}{l}\text { HFE H63D } \\
\text { genotypes/alleles }\end{array}$ & OR (95\%CI) & $\boldsymbol{p}$-value & OR $(\mathbf{9 5 \% C I})^{*}$ & $\boldsymbol{p}$-value* \\
\hline CC vs. GG & $0.818(0.240-2.785)$ & $0.751^{* *}$ & $1.965(0.444-8.697)$ & 0.374 \\
CC vs. GC & $0.931(0.564-1.536)$ & 0.780 & $0.828(0.455-1.506)$ & 0.536 \\
GC vs. GG & $0.879(0.245-3.152)$ & $1.000^{* *}$ & $2.224(0.454-10.896)$ & $0.324 * *$ \\
CC vs. GC+ GG & $0.917(0.569-1.480)$ & 0.724 & $0.919(0.520-1.625)$ & 0.772 \\
GG vs. GC+CC & $1.202(0.355-4.067)$ & $0.754^{* *}$ & $0.487(0.111-2.139)$ & 0.341 \\
GC vs. CC+GG & $1.066(0.647-1.754)$ & 0.802 & $1.237(0.684-2.236)$ & 0.482 \\
C vs. G & $0.915(0.601-1.394)$ & 0.680 & & \\
\hline
\end{tabular}

$O R$ odds ratio, $C I$ confidence interval

*Adjusted for gender and age

** Fisher's exact test 2-sided

*** Hosmer-Lemeshow test $p$-value $<0.05$ 
Table 4 Frequency distribution analysis in episodic and chronic cluster headache $(\mathrm{CH})$ patients for the HFE H63D variant

\begin{tabular}{|c|c|c|c|c|c|c|c|c|}
\hline \multirow[t]{2}{*}{ Genotypes/alleles } & \multicolumn{2}{|c|}{$\begin{array}{l}\text { Episodic CH } \\
(N=\mathbf{8 5})\end{array}$} & \multicolumn{2}{|c|}{$\begin{array}{l}\text { Chronic CH } \\
(N=\mathbf{3 8})\end{array}$} & \multirow[t]{2}{*}{ OR $(95 \% \mathrm{CI})$} & \multirow[t]{2}{*}{$p$-value } & \multirow[t]{2}{*}{ OR $(95 \% \mathrm{CI})^{*}$} & \multirow[t]{2}{*}{$p$-value* } \\
\hline & $n$ & $(\%)$ & $n$ & $(\%)$ & & & & \\
\hline $\mathrm{CC}$ & 67 & $(78.8)$ & 23 & $(60.5)$ & 1.0 (reference) & - & - & - \\
\hline GC & 16 & $(18.8)$ & 13 & $(34.2)$ & $2.367(0.990-5.659)$ & 0.049 & $2.322(0.963-5.599)$ & 0.061 \\
\hline GG & 2 & $(2.4)$ & 2 & $(5.3)$ & $2.913(0.388-21.880)$ & $0.287 * *$ & $3.170(0.402-24.989)$ & 0.273 \\
\hline $\mathrm{GC}+\mathrm{GG}$ & 18 & $(21.2)$ & 15 & $(39.5)$ & $2.428(1.055-5.584)$ & 0.034 & $2.443(1.051-5.679)$ & 0.038 \\
\hline GG & 2 & $(2.4)$ & 2 & $(5.3)$ & 1.0 (reference) & - & - & - \\
\hline GC & 16 & $(18.8)$ & 13 & $(34.2)$ & $1.231(0.152-9.972)$ & $1.000 * *$ & $0.362(0.033-4.031)$ & 0.409 \\
\hline $\mathrm{GC}+\mathrm{CC}$ & 83 & (97.6) & 36 & $(94.7)$ & $0.434(0.059-3.200)$ & $0.587 * *$ & $0.372(0.049-2.842)$ & 0.341 \\
\hline GC & 16 & $(18.8)$ & 13 & $(34.2)$ & $1.0($ reference $)$ & - & - & - \\
\hline $\mathrm{CC}+\mathrm{GG}$ & 69 & $(81.2)$ & 25 & $(65.8)$ & $0.446(0.188-1.057)$ & 0.063 & $0.453(0.189-1.087)$ & 0.076 \\
\hline $\mathrm{C}$ & 150 & $(88.8)$ & 59 & $(77.6)$ & 1.0 (reference) & - & - & - \\
\hline G & 20 & (11.8) & 17 & (22.4) & $2.161(1.059-4.410)$ & 0.032 & - & - \\
\hline
\end{tabular}

$O R$ odds ratio, $C I$ confidence interval

*Adjusted for gender and age

***Fisher's exact test 2-sided

association between this $H F E$ variant and $\mathrm{CH}$ risk susceptibility in SECs. Nonetheless, the stratified genotypic and allelic analyses according to $\mathrm{CH}$ subgroups (episodic and chronic $\mathrm{CH}$ ) showed that the variant $\mathrm{G}$ allele was significantly more prevalent in chronic compared to episodic $\mathrm{CH}$ patients, conferring an increased risk for disease chronification for the patients carrying the variant $\mathrm{G}$ allele. Thus, although it is unlikely that $H F E$ genetic variation contributes considerably to $\mathrm{CH}$ genetic susceptibility, a potential role for $H F E$ as a disease modifier gene may be regarded.

The possible molecular mechanisms interpreting the findings of the current study are not clear. As mentioned, various studies suggested a correlation between increased iron deposits in brainstem pain-processing structures and primary headaches. The HFE protein is expressed in the brain along with TfR; thus, variants in the $H F E$ gene may influence brain iron uptake. $H F E$ variants are related with enhanced iron accumulation (Bell et al. 2021); therefore, H63D variant might regulate iron deposition in brain pain-modulating centers and contribute to brain iron overload and increased oxidative stress states. Iron overload may alter the threshold for headache triggering, rendering carriers of $H F E$ variants more susceptible to environmental challenges and/or other genetic modifiers (Nandar and Connor 2011; Nandar et al. 2013). Moreover, the presence of $H F E$ variant genotypes may confer susceptibility for $\mathrm{CH}$ even in the absence of enhanced iron deposits. Lastly, a correlation between irondeficiency anemia (IDA) and the incidence of migraine was suggested (Gür-Özmen and Karahan-Özcan 2015; Tayyebi et al. 2019). To maximize iron absorption in IDA, hepcidin levels are usually repressed (Girelli et al. 2016; Dewan et al. 2019). Since the HFE protein is involved in the regulation of hepcidin expression, the underlying biological mechanism may be associated with defective hepcidin pathway.

Only one previously reported study by Rainero et al. investigated the impact of $\mathrm{C} 282 \mathrm{Y}$ and $\mathrm{H} 63 \mathrm{D}$ HFE missense polymorphisms on $\mathrm{CH}$ occurrence and clinical features, in an Italian cohort of $109 \mathrm{CH}$ patients and 211 age-matched and geographically matched healthy controls. They observed no C282Y variant in the Northern Italian population of the cohort, whereas, similarly to the current study, they concluded that the examined $H F E$ variants are not significantly associated with $\mathrm{CH}$. On the contrary, they found no significant difference between episodic and chronic $\mathrm{CH}$ patients. The lack of statistically significant difference may be attributed to the small number of chronic $\mathrm{CH}$ patients included in the Italian $\mathrm{CH}$ cohort (14 chronic $\mathrm{CH}$ patients) and the absence of D63D genotype carriers in the chronic $\mathrm{CH}$ subgroup. Lastly, they observed a later age of disease onset in the four D63D homozygous patients, indicative of an involvement of HFE gene in disease modification (Rainero et al. 2005). An association study in an Italian population of 256 migraine patients and 237 healthy age-, sex-, and ethnicitymatched controls showed that patients with the H63D GG (D63D) genotype presented significantly later age of disease onset and increased frequency of migraine attacks, concluding that the HFE H63D variant may be a modifying genetic factor in migraine (Rainero et al. 2007).

Certain limitations of the current study should be acknowledged. Firstly, the relatively small sample size may not be sufficient to reveal small effects of the examined genetic variants in $\mathrm{CH}$. Secondly, the study population was enrolled from a particular geographical area and does not consist of ethnically or racially different populations to avoid 
population selection bias; thus, it should be considered when interpreting the results in other populations. Other potential bias might be the difference in gender ratio and age distribution between case and control subjects, although an adjustment in statistical analysis of the results was performed. Finally, the study did not evaluate confounding factors such as gene-gene or gene-environment interactions which may possibly influence $\mathrm{CH}$ phenotypes.

\section{Conclusion}

Even though $\mathrm{CH}$ is regarded as a multifactorial primary headache disorder with both genetic and environmental inputs, the phenotypic variability defined by genetic variation is still uncertain. The results of the current study did not provide supportive evidence for significant association between the investigated $H F E$ gene variant and $\mathrm{CH}$ susceptibility in the SEC population; hence, $H F E$ gene might not be considered as a genetic risk factor for $\mathrm{CH}$. Nevertheless, a correlation between H63D HFE variant and disease progression could be perceived; thus, in accordance with previous studies in primary headaches, HFE may serve as a candidate disease modifier gene. More, larger scaled studies in different populations, considering gene-gene and gene-environment interactions as well as additional iron metabolism regulating genes and biochemical parameters should be followed to elucidate the precise role of HFE and iron homeostasis in $\mathrm{CH}$ pathophysiology and their possible involvement in $\mathrm{CH}$ genetic susceptibility and diverse phenotypic characteristics. Detecting the underlying genetic components may potentially unravel the molecular pathways implicated in disease pathophysiology and facilitate the development of novel therapeutic targets.

Author Contribution MP, MSK, and ND conceptualized and designed the study. MV, VS, ED, and ED contributed to clinical data and sample collection. MP prepared the samples and performed the research. KK genotyped samples. MP and CP performed the statistical analyses. MP wrote the manuscript. GL contributed to the final editing. All authors read and approved the final manuscript.

Availability of Data and Material Available upon reasonable request

Code Availability Not applicable.

\section{Declarations}

Ethics Approval Approval was obtained from the ethics committee of Mediterraneo Hospital, Glyfada, Greece, and from the University Hospital of Larissa Ethics Committee. The study was performed in line with the principles of the Declaration of Helsinki.
Consent to Participate All individual participants included in the study gave prior written informed consent.

Consent for Publication All participants provided written informed consent for publication of any associated data.

Conflict of Interest The authors declare no competing interests.

Open Access This article is licensed under a Creative Commons Attribution 4.0 International License, which permits use, sharing, adaptation, distribution and reproduction in any medium or format, as long as you give appropriate credit to the original author(s) and the source, provide a link to the Creative Commons licence, and indicate if changes were made. The images or other third party material in this article are included in the article's Creative Commons licence, unless indicated otherwise in a credit line to the material. If material is not included in the article's Creative Commons licence and your intended use is not permitted by statutory regulation or exceeds the permitted use, you will need to obtain permission directly from the copyright holder. To view a copy of this licence, visit http://creativecommons.org/licenses/by/4.0/.

\section{References}

Barton JC, Edwards CQ, Acton RT (2015) HFE gene: structure function mutations and associated iron abnormalities. Gene 574:179192. https://doi.org/10.1016/j.gene.2015.10.009

Bell S, Rigas AS, Magnusson MK et al (2021) A genome-wide metaanalysis yields 46 new loci associating with biomarkers of iron homeostasis. Commun Biol 4:156. https://doi.org/10.1038/ s42003-020-01575-Z

D’Amico D, Centonze V, Grazzi L et al (1997) Coexistence of migraine and cluster headache: report of 10 cases and possible pathogenetic implications. Headache J Head Face Pain 37:21-25. https://doi. org/10.1046/j.1526-4610.1997.3701021.x

Dewan P, Dixit A, Gomber S et al (2019) Serum and urinary hepcidin for diagnosing iron-deficiency anemia in under-5 children. J Pediatr Hematol Oncol 41:e216-e220. https://doi.org/10.1097/MPH. 0000000000001320

Domínguez C, López A, Ramos-Cabrer P et al (2019) Iron deposition in periaqueductal gray matter as a potential biomarker for chronic migraine. Neurology 92:e1076-e1085. https://doi.org/10.1212/ WNL.0000000000007047

Dupont WD, Plummer WD (1990) Power and sample size calculations. Control Clin Trials 11:116-128. https://doi.org/10.1016/ 0197-2456(90)90005-M

Fan Z, Hou L, Wan D et al (2018) Genetic association of HCRTR2 ADH4 and CLOCK genes with cluster headache: a Chinese population-based case-control study. J Headache Pain 19:1. https://doi.org/10.1186/s10194-017-0831-1

Fourier C, Ran C, Steinberg A et al (2019) Analysis of HCRTR2 gene variants and cluster headache in Sweden. Headache J Head Face Pain 59:410-417. https://doi.org/10.1111/head.13462

Gibson KF, Dos SA, Lund N et al (2019) Genetics of cluster headache. Cephalalgia 39:1298-1312. https://doi.org/10.1177/0333102418815503

Girelli D, Nemeth E, Swinkels DW (2016) Hepcidin in the diagnosis of iron disorders. Blood 127:2809-2813. https://doi.org/10.1182/ blood-2015-12-639112

Goadsby PJ (2018) Cluster headache and the trigeminal-autonomic reflex: driving or being driven? Cephalalgia 38:1415-1417. https://doi.org/10.1177/0333102417738252 
Gür-Özmen S, Karahan-Özcan R (2015) Iron deficiency anemia is associated with menstrual migraine: a case-control study. Pain Med 17:pnv029. https://doi.org/10.1093/pm/pnv029

Hagen K, Stovner LJ, Åsberg A et al (2002) High headache prevalence among women with hemochromatosis: the Nord-Trøndelag health study. Ann Neurol 51:786-789. https://doi.org/10.1002/ana.10209

Headache Classification Committee of the International Headache Society (IHS) (2018) The International Classification of Headache Disorders 3rd edition. Cephalalgia 38:1-211. https://doi.org/10. $1177 / 0333102417738202$

Jiang H, Wang J, Rogers J, Xie J (2017) Brain iron metabolism dysfunction in Parkinson's Disease. Mol Neurobiol 54:3078-3101. https://doi.org/10.1007/s12035-016-9879-1

Katsarou M-S, Latsi R, Papasavva M et al (2016) Population-based analysis of the frequency of HFE gene polymorphisms: correlation with the susceptibility to develop hereditary hemochromatosis. Mol Med Rep 14:630-636. https://doi.org/10.3892/mmr.2016. 5317

Katsarou M-S, Papasavva M, Latsi R, Drakoulis N (2019) Hemochromatosis: hereditary hemochromatosis and HFE gene. Vitam Horm 110:201-222. https://doi.org/10.1016/bs.vh.2019.01.010

Kent P, Wilkinson N, Constante M et al (2015) Hfe and Hjv exhibit overlapping functions for iron signaling to hepcidin. J Mol Med 93:489-498. https://doi.org/10.1007/s00109-015-1253-7

Kim Y, Connor JR (2020) The roles of iron and HFE genotype in neurological diseases. Mol Aspects Med 75:100867. https://doi.org/ 10.1016/j.mam.2020.100867

Kruit M, Launer L, Overbosch J et al (2009) Iron accumulation in deep brain nuclei in migraine: a population-based magnetic resonance imaging study. Cephalalgia 29:351-359. https://doi.org/10.1111/j. 1468-2982.2008.01723.x

Kudrow L, Kudrow DB (1994) Inheritance of cluster headache and its possible link to migraine. Headache J Head Face Pain 34:400 407. https://doi.org/10.1111/j.1526-4610.1994.hed3407400.x

Láinez MJA, Guillamón E (2017) Cluster headache and other TACs: pathophysiology and neurostimulation options. Headache J Head Face Pain 57:327-335. https://doi.org/10.1111/head.12874

Liampas I, Siokas V, Brotis A et al (2020) Meta-analysis of melatonin levels in cluster headache-review of clinical implications. Acta Neurol Scand 142:356-367. https://doi.org/10.1111/ane.13317

Nandar W, Connor JR (2011) HFE gene variants affect iron in the brain. J Nutr 141:729-739. https://doi.org/10.3945/jn.110.130351

Nandar W, Neely EB, Unger E, Connor JR (2013) A mutation in the HFE gene is associated with altered brain iron profiles and increased oxidative stress in mice. Biochim Biophys Acta 1832:729-741. https://doi.org/10.1016/j.bbadis.2013.02.009

Nixon AM, Neely E, Simpson IA, Connor JR (2018) The role of HFE genotype in macrophage phenotype. J Neuroinflammation 15:111. https://doi.org/10.1186/s12974-018-1057-0

O'connor E, Simpson BS, Houlden H et al (2020) Prevalence of familial cluster headache: a systematic review and meta-analysis. J Headache Pain 21:1-10. https://doi.org/10.1186/s10194-020-01101-w

Palm-Meinders IH, Koppen H, Terwindt GM et al (2017) Iron in deep brain nuclei in migraine? CAMERA follow-up MRI findings. Cephalalgia 37:795-800. https://doi.org/10.1177/0333102416668654

Pantopoulos K (2018) Inherited disorders of iron overload. Front Nutr 5:1-11. https://doi.org/10.3389/fnut.2018.00103

Pantopoulos K (2008) Function of the hemochromatosis protein HFE: lessons from animal models. World J Gastroenterol 14:6893-6901

Papasavva M, Katsarou M-S, Vikelis M et al (2020) Analysis of HCRTR2, GNB3, and ADH4 gene polymorphisms in a southeastern European Caucasian cluster headache population. J Mol Neurosci 70:467-474. https://doi.org/10.1007/s12031-019-01439-0

Pinessi L, Rainero I, Rivoiro C et al (2005) Genetics of cluster headache: an update. J Headache Pain 6:234-236. https://doi.org/10. 1007/s10194-005-0194-x
Rainero I, Rivoiro C, Rubino E et al (2005) Prevalence of HFE (hemochromatosis) gene mutations in patients with cluster headache. Headache 45:1219-1223. https://doi.org/10.1111/j.1526-4610. 2005.00245.x

Rainero I, Rubino E, Rivoiro C et al (2007) Haemochromatosis gene (HFE) polymorphisms and migraine: an association study. Cephalalgia 27:9-13. https://doi.org/10.1111/j.1468-2982.2006.01231.x

Ran C, Fourier C, Michalska JM et al (2017) Screening of genetic variants in ADCYAP1R1 MME and 14q21 in a Swedish cluster headache cohort. J Headache Pain 18:88. https://doi.org/10.1186/ s10194-017-0798-y

Ran C, Michalska JM, Fourier C et al (2020) Analysis of NOS gene polymorphisms in relation to cluster headache and predisposing factors in Sweden. Brain Sci 11:34. https://doi.org/10.3390/ brainsci11010034

Rodriguez S, Gaunt TR, Day INM (2009) Hardy-Weinberg equilibrium testing of biological ascertainment for mendelian randomization studies. Am J Epidemiol 169:505-514. https://doi.org/10.1093/ aje/kwn359

Russell MB (2004) Epidemiology and genetics of cluster headache. Lancet Neurol 3:279-283. https://doi.org/10.1016/S14744422(04)00735-5

Schürks M (2010) Genetics of cluster headache. Curr Pain Headache Rep 14:132-139. https://doi.org/10.1007/s11916-010-0096-8

Sjöstrand C, Modin H, Masterman T et al (2002) Analysis of nitric oxide synthase genes in cluster headache. Cephalalgia 22:758 764. https://doi.org/10.1046/j.1468-2982.2002.00452.x

Snoer A, Lund N, Beske R et al (2018) Pre-attack signs and symptoms in cluster headache: characteristics and time profile. Cephalalgia 38:1128-1137. https://doi.org/10.1177/0333102417726498

Stoffel NU, Lazrak M, Bellitir S et al (2019) The opposing effects of acute inflammation and iron deficiency anemia on serum hepcidin and iron absorption in young women. Haematologica 104:11431149. https://doi.org/10.3324/haematol.2018.208645

Stovner L, Hagen K, Waage A, Bjerve K (2002) Hereditary haemochromatosis in two cousins with cluster headache. Cephalalgia 22:317-319. https://doi.org/10.1046/j.1468-2982.2002.00367.x

Tayyebi A, Poursadeghfard M, Nazeri M, Pousadeghfard T (2019) Is there any correlation between migraine attacks and iron deficiency anemia? A case-control study. Int J Hematol Stem Cell Res 13:164-171. https://doi.org/10.18502/ijhoscr.v13i3.1276

Tepper SJ, Lowe MJ, Beall E et al (2012) Iron deposition in painregulatory nuclei in episodic migraine and chronic daily headache by MRI. Headache J Head Face Pain 52:236-243. https://doi.org/ 10.1111/j.1526-4610.2011.02056.x

Traeger L, Enns CA, Krijt J, Steinbicker AU (2018) The hemochromatosis protein HFE signals predominantly via the BMP type I receptor ALK3 in vivo. Commun Biol 1:1-7. https://doi.org/10. 1038/s42003-018-0071-1

Vikelis M, Rapoport AM (2016) Cluster headache in Greece: an observational clinical and demographic study of 302 patients. J Headache Pain 17:88. https://doi.org/10.1186/s10194-016-0683-0

Wang Z-X, Wan Y, Tan L et al (2017) Genetic association of HLA gene variants with MRI brain structure in Alzheimer's disease. Mol Neurobiol 54:3195-3204. https://doi.org/10.1007/ s12035-016-9889-z

Waung MW, Taylor A, Qualmann KJ, Burish MJ (2020) Family history of cluster headache. JAMA Neurol 77:887. https://doi.org/ 10.1001/jamaneurol.2020.0682

Welch KMA, Nagesh V, Aurora SK, Gelman N (2001) Periaqueductal gray matter dysfunction in migraine: cause or the burden of illness? Headache 41:629-637. https://doi.org/10.1046/j.1526-4610. 2001.041007629.x

Wu Q, Wang H, An P et al (2015) HJV and HFE play distinct roles in regulating hepcidin. Antioxidants Redox Signal 22:1325-1336. https://doi.org/10.1089/ars.2013.5819 
Zarrilli F, Tomaiuolo R, Ceglia C et al (2015) Molecular analysis of cluster headache. Clin J Pain 31:52-57. https://doi.org/10.1097/ AJP.0000000000000075
Publisher's Note Springer Nature remains neutral with regard to jurisdictional claims in published maps and institutional affiliations. 